\title{
Lacaziosis in bottlenose dolphins Tursiops truncatus along the coastal Atlantic Ocean, Florida, USA
}

\author{
M. Elizabeth Murdoch ${ }^{1, *}$, Marilyn Mazzoil ${ }^{1}$, Stephen McCulloch ${ }^{1}$, Sarah Bechdel ${ }^{1}$, \\ Greg O'Corry-Crowe ${ }^{1}$, Gregory D. Bossart ${ }^{2}$, John S. Reif ${ }^{3}$ \\ ${ }^{1}$ Harbor Branch Oceanographic Institute at Florida Atlantic University Center for Marine Ecosystem Health - \\ Marine Mammal Research \& Conservation, 5600 US 1 North, Fort Pierce, Florida 34946, USA \\ ${ }^{2}$ Georgia Aquarium, 225 Baker Street, Atlanta, Georgia 30313, USA \\ ${ }^{3}$ Colorado State University, Department of Environmental and Radiological Health Sciences, Fort Collins, Colorado 80523, USA
}

\begin{abstract}
This study represents the first systematic study of lacaziosis (lobomycosis) in bottlenose dolphins Tursiops truncatus in the Atlantic Ocean along the east-central coast of Florida, USA. Lacaziosis is a chronic infection of the skin caused by the fungus Lacazia loboi, which affects only dolphins and humans. Previous studies have shown a high prevalence (6.8 to $12.0 \%$ ) of lacaziosis in resident dolphins from the adjacent Indian River Lagoon Estuary (IRL), where the disease is endemic. We examined the prevalence of lacaziosis in this coastal area using photo-identification data collected between 2002 and 2008 to determine the prevalence of lacaziosis in coastal dolphins using photographic methodology shown to have high sensitivity and specificity in prior research. The prevalence of skin lesions compatible with lacaziosis estimated from photographic data was $2.1 \%$ (6/284), approximately 3 times lower than that described for the estuarine population using similar methods. To exclude potential bias introduced by differences in study duration and survey effort among areas, an 18 mo period when effort was most equal (January 2006 to June 2007) was chosen for statistical comparison. The prevalence of lacaziosis estimated from photographic data was significantly lower $(3.8 \%: n=6 / 160)$ in the Atlantic Ocean compared to the IRL $(12.0 \%: n=20 / 167)$ (risk ratio $=3.19,95 \%$ CI 1.32 to $7.75, \mathrm{p}<0.01$ by chi-square analysis). The lower prevalence of lacaziosis in dolphins found in the Atlantic Ocean and the overall lack of movement of dolphins between these habitats suggests that environmental conditions within the estuary may favor viability of $L$. loboi, and/or that immune compromise in resident estuarine dolphins is a precursor to the disease.
\end{abstract}

KEY WORDS: Bottlenose dolphin $\cdot$ Ecosystem health $\cdot$ Epidemiology $\cdot$ Fungal disease $\cdot$ Lacaziosis Photo-identification

\section{INTRODUCTION}

Lacaziosis is a chronic mycotic disease of the skin and subcutaneous tissues that affects only dolphins and humans. It is caused by the yeast-like organism Lacazia loboi, which is found abundantly within lesions (Taborda et al. 1999) but has not yet been cultured. Lacaziosis is characterized by the appearance of cutaneous nodules that grow slowly over many years in both species (Rodriguez-Toro 1993, Reif et al. 2006). Lesions in humans develop on the exposed areas of the body, particularly the extremities, face and ears (Fuchs et al. 1990, Rodriguez-Toro 1993). Human lacaziosis is endemic in rural areas of South and Central America among persons with contact with water, soil and vegetation (Rodriguez-
Toro 1993) and has also occurred among persons who have traveled to an endemic area (Elsayed et al. 2004).

Dermal lesions in bottlenose dolphins Tursiops truncatus are similar to those described in humans but may be more extensive, covering large areas of the body. Lesions are found on the dorsal and pectoral fins, the head, fluke and caudal peduncle, where they form multiple aggregations of firm, white raised nodules that may extend $>30 \mathrm{~cm}$ in the broadest dimension (Reif et al. 2006). Lesions may be associated with sites of apparent previous trauma, such as shark bites (Murdoch et al. 2008). Many dolphins with lacaziosis have significant impairment in adaptive immunity, suggesting that the disease in dolphins may represent an opportunistic infection in an immune-compromised host (Reif et al. 2008). 
Lacaziosis was first identified in dolphins along the Gulf coast of Florida, USA (Migaki et al. 1971), in the Indian River Lagoon, FL (Caldwell et al. 1975) and in a dolphin from Marineland, FL (Woodard, 1972) in the 1970s. Cases were also reported from the Surinam River estuary (De Vries \& Laarman 1973), the SpanishFrench coast (Symmers 1983), the intracoastal waterway in south Florida (Bossart 1984), the southern Brazilian coast (Simõse-Lopes et al. 1993), and the Texas coast of the Gulf of Mexico (Cowan 1993).

The Indian River Lagoon (IRL) is a unique coastal ecosystem that extends $250 \mathrm{~km}$ along the east-central coast of Florida. The IRL is connected to the Atlantic Ocean via 5 inlets and the Canaveral Lock. Long-term, year-round resident dolphins have been observed in the estuary (Mazzoil et al. 2005), and at least 3 distinct communities have been identified within the population (Mazzoil et al. 2008). Recent research has provided evidence for distinct populations in both the IRL Estuary and Atlantic Ocean population(s) (Mazzoil et al. 2010).

Our previous studies have shown a high prevalence of lacaziosis in resident dolphins from the Indian River Lagoon Estuary, where the disease is endemic. Lacaziosis was described in single dolphin the IRL in 1984 (Bossart 1984) and in series of stranded dolphins in which 3 of 17 (17.6\%) had histopathologic evidence of infection between 2001 and 2002 (Bossart et al. 2003). In a cross-sectional study of 75 dolphins caught and released during a health assessment from 2003 to 2005, the prevalence was $12.0 \%$ (Reif et al. 2006). In a retrospective analysis of 704 IRL dolphins assessed for photographic evidence of lesions indicative of lacaziosis, the prevalence was $6.8 \%$ (Murdoch et al. 2008). NokeDurden et al. (2009) confirmed lacaziosis histologically in $9 \%(3 / 33)$ of stranded dolphins in the northern IRL.

Recent reports have described confirmed or presumed lacaziosis (lacaziosis-like disease, LLD, based on photographic assessment; Van Bressem et al. 2007) in Delphinidae from coastal areas around the world including Ecuador, Peru, and Columbia (Van Bressem et al. 2007), Brazil (Van Bressem et al. 2007, 2009), Venezuela (Bermudez et al. 2009), and Mayotte in the Indian Ocean (Kiszka et al. 2009). With a single, notable exception, all cases of lacaziosis reported in United States waters up to this point have been in coastal or estuarine bottlenose dolphins. Rotstein et al. (2009) recently reported lacaziosis in 2 stranded offshore bottlenose dolphins and LLD in one wild offshore bottlenose dolphin off the coast of North Carolina, USA. The possible presence of lacaziosis in this offshore ecotype, which is generally found more than $7.5 \mathrm{~km}$ from shore (Torres et al. 2003), at a significantly higher latitude than previously described, suggests that the distribution of the disease could be broader than previously reported. Further exploration of the spatial patterns of lacaziosis is needed to clarify the epidemiologic characteristics of the disease and to explore potential environmental exposures that may contribute to its occurrence.

We undertook the current investigation in order to (1) document the prevalence of lacaziosis in dolphins inhabiting the coastal Atlantic waters in Florida using photographic methodology shown to have high sensitivity and specificity in our prior research; and (2) compare the prevalence of lacaziosis in the Atlantic Ocean population to the adjacent Indian River Lagoon population.

\section{MATERIALS AND METHODS}

Survey area. The Atlantic Ocean was surveyed from $27^{\circ} 53^{\prime} \mathrm{N}$ to $27^{\circ} 08^{\prime} \mathrm{N}$ (Fig. 1). The survey route provided visual access from the track to the beach $(1.5 \mathrm{~km})$ and to at least $3 \mathrm{~km}$ offshore. The survey route encompassed 3 inlets, originating at Ft. Pierce Inlet and extending $2 \mathrm{~km}$ north of Sebastian Inlet $(45 \mathrm{~km})$ or $2 \mathrm{~km}$ south of St. Lucie Inlet (35 km).

Photo-identification research and presumed lacaziosis assessment. Exploratory photographic surveys were randomly conducted from Sebastian to St. Lucie Inlets from October 2002 to October 2005, with one survey reaching as far south as Jupiter Inlet. System-



Fig. 1. Survey areas of the coastal Atlantic Ocean and Indian River Lagoon, Florida, USA. Dashed line: survey route 
atic photographic surveys of dolphins were conducted once monthly from February 2006 to August 2008. Both 'on' and 'off' surveys were included in the analyses, 'on' survey referring to time spent actively searching for dolphins along the survey route and 'off' surveying referring to time spent traveling to survey destinations and returning to port.

Photo-identification methods have been described previously (Mazzoil et al. 2004). We followed the classification scheme for identifying presumed evidence of lacaziosis described by Murdoch et al. (2008). Briefly stated, the analysis was limited to areas of body visible during surfacing (e.g. the dorsal fin and dorsal areas of the head and peduncle). All photographs were initially reviewed by a single investigator (M. E. Murdoch), and those with skin lesions compatible with lacaziosis were reviewed independently by a second investigator (J. S. Reif). Dolphins were classified as presumed lacaziosis when both reviewers agreed on the assessment.

Population comparison. The estimated prevalences of presumed lacaziosis in the Atlantic Ocean and IRL were compared for the 18 mo period between January 2006 and June 2007, divided into 3 mo intervals. This period was chosen since the survey effort was similar between the 2 areas (once-monthly surveys of the study area at each site). The analysis was further restricted to the same latitudes in the 2 study areas $\left(27^{\circ} 53^{\prime} \mathrm{N}\right.$ to $\left.27^{\circ} 08^{\prime} \mathrm{N}\right)$.

Analysis. The incidence rate for each quarter and site was calculated by dividing the newly identified presumed lacaziosis cases for the quarter by the number of dolphins sighted during that quarter minus previously identified cases. The cumulative prevalence of lacaziosis for each quarter was calculated by dividing the number of prevalent cases by the total number of known dolphins in the population. The numerator for each quarterly prevalence rate included newly identified cases as well as cases diagnosed previously. The denominator for each prevalence rate included the total identified population by the end of the preceding quarter. The overall prevalence rate was calculated by dividing the total number of presumed cases by the total number of identified dolphins for the entire study period. The total prevalence for the 18 mo period was compared between sites by calculating the risk ratio with its $95 \%$ confidence interval. Statistical significance of the difference between sites was also compared with a chi-square test, with $\mathrm{p}<0.05$ considered significant.

\section{RESULTS}

A total of 284 distinctly marked individuals were identified in the Atlantic Ocean during 204 encounters ('on' and 'off' survey) from 2002 to 2008. Six of the 284
$(2.1 \%)$ distinct dolphins in the study area were found to have lesions consistent with lacaziosis. This prevalence estimate is less than one-third of the corresponding estimate for the entire IRL based on 704 distinct dolphins sighted between 1996 and 2006 using similar techniques. All Atlantic Ocean dolphins identified with presumed lacaziosis were sighted between Ft. Pierce Inlet and Sebastian Inlet; no cases occurred between Ft. Pierce Inlet and St. Lucie Inlet (Fig. 1). All 6 cases were sighted during the 18 mo time period from January 2006 to June 2010, when monthly surveys were conducted in each area.

The first case of presumed lacaziosis seen in the Atlantic Ocean occurred in 2004. Two of the 6 cases were first identified in 2006 and the remaining 3 were sighted in 2007. Of the 6 cases of presumed lacaziosis, 3 dolphins were seen only once in the study area, 2 dolphins were sighted twice, and 1 dolphin was sighted 4 times.

During the 18 mo (January 2006 to June 2007) comparison period, 160 distinctly marked dolphins were identified in the coastal Atlantic population. Of these 160 individuals, 6 presumed cases of lacaziosis were seen, a prevalence of $3.8 \%$. During the same time period, 167 individuals were identified in the Indian River Lagoon population with only 2 dolphins (a cow/calf pair without presumed lacaziosis) observed in both survey areas (Mazzoil et al. 2010). In the IRL, 20 dolphins exhibited evidence of presumed lacaziosis, a prevalence of $12.0 \%$ (Table 1 ). The risk ratio was 3.19, $95 \%$ CI 1.32 to 7.75 , p < 0.01 by chi square analysis.

As shown in Fig. 2, the incidence rate of lacaziosis in the Atlantic Ocean population had little fluctuation $(0.65$ to $2.2 \%)$ whereas the rate in the IRL population decreased dramatically from 9.23 to $0.68 \%$ over 18 mo. The prevalence of lacaziosis in the coastal Atlantic population varied over time from a high of $4.17 \%$ to a low of $1.4 \%$. The prevalence in the Indian River Lagoon population rose gradually from 9.23 to $11.98 \%$.

\section{DISCUSSION}

Photographic evaluation has proven to be a useful tool to monitor the course of individual and population health for lacaziosis in the IRL population (Murdoch et al. 2008). In our previous work, we showed that photographic assessment had a sensitivity of $75 \%$ and a specificity of $100 \%$ (Murdoch et al. 2008). Although false positive diagnoses of lacaziosis could arise by confusion with other skin disorders such as necrotizing, hyperplastic dermatitis with invasive protozoa (Bossart et al. 2003), we found no such instances in 12 cases of presumed lacaziosis after histological examination of tissues (Murdoch et al. 2008). 
Table 1. Tursiops truncatus. Incidence and cumulative prevalence rates of presumed lacaziosis identified during photo-identification surveys of the coastal Atlantic Ocean (ATL) population and the Indian River Lagoon (IRL) population, Florida, USA, January 2006 to June 2007. Incidence calculated as: new lacaziosis cases/(no. of identified dolphins per quarter - previous cases). Prevalence calculated as total prevalent cases divided by total distinct dolphins

\begin{tabular}{|c|c|c|c|c|c|c|}
\hline $\begin{array}{l}\text { Quarter } \\
\text { and year }\end{array}$ & $\begin{array}{c}\text { Identified } \\
\text { dolphins } \\
\text { (per quarter) }\end{array}$ & $\begin{array}{c}\text { New } \\
\text { lacaziosis } \\
\text { cases }\end{array}$ & $\begin{array}{c}\text { Quarterly } \\
\text { incidence } \\
\text { rate }\end{array}$ & $\begin{array}{c}\text { Total } \\
\text { identified } \\
\text { dolphins }\end{array}$ & $\begin{array}{l}\text { Total } \\
\text { prevalent } \\
\text { cases }\end{array}$ & Prevalence \\
\hline \multicolumn{7}{|l|}{ ATL } \\
\hline $1-2006$ & 50 & 1 & 2.00 & 50 & 1 & 2 \\
\hline $2-2006$ & 21 & 0 & 0.00 & 71 & 1 & 1.4 \\
\hline $3-2006$ & 33 & 2 & 6.25 & 93 & 3 & 3.23 \\
\hline $4-2006$ & 19 & 0 & 0.00 & 99 & 3 & 3.03 \\
\hline $1-2007$ & 33 & 2 & 6.67 & 120 & 5 & 4.17 \\
\hline $2-2007$ & 47 & 1 & 2.22 & 160 & 6 & 3.75 \\
\hline \multicolumn{7}{|l|}{ IRL } \\
\hline $1-2006$ & 130 & 12 & 9.23 & 130 & 12 & 9.23 \\
\hline $2-2006$ & 104 & 2 & 2.17 & 153 & 14 & 9.15 \\
\hline $3-2006$ & 87 & 2 & 2.74 & 157 & 16 & 10.19 \\
\hline $4-2006$ & 99 & 2 & 2.41 & 162 & 18 & 11.11 \\
\hline $1-2007$ & 120 & 1 & 0.98 & 164 & 19 & 11.59 \\
\hline $2-2007$ & 121 & 1 & 0.98 & 167 & 20 & 11.98 \\
\hline
\end{tabular}



Fig. 2. Tursiops truncatus. Prevalence of lacaziosis in bottlenose dolphins from the coastal Atlantic Ocean (ATL) and Indian River Lagoon (IRL), Florida, USA, populations

Lacazia loboi has not been cultured in vitro and the conditions for its environmental persistence are unknown. The organism may have strict requirements for temperature, salinity and other parameters to survive in the marine environment. The conditions within the southern area of the IRL estuary may favor viability of L. loboi since it is characterized by freshwater incursion, lower salinity, and higher average water temperatures (MRC 2003). Fungal growth and persistence within the estuary may also explain the significantly higher prevalence of lacaziosis (6.8 to $12.0 \%$ ) in the IRL compared to that for dolphins in the Atlantic Ocean (2.1\%).

With the single, rare exception of lacaziosis in an aquarium attendant, lacaziosis is not known to be transmitted horizontally by dolphin to dolphin or dolphin to human contact (Symmers 1983) under natural conditions. However, a reported laboratory accident in which human lacaziosis was acquired from experimentally infected mice (Rosa et al. 2009) and successful serial pas- sage of Lacazia loboi in mice by footpad injection (Belone et al. 2002) support the concept of horizontal transmission under highly unusual circumstances that could include mother to calf transmission (Kiszka et al. 2009) and accidental inoculation. The preponderance of evidence suggests that the infection is acquired from the local environment in both humans (Rodriguez-Toro 1998) and dolphins (Reif et al. 2006). Lacaziosis in Atlantic Ocean dolphins could theoretically occur from exposure to contaminated water filtered through inlets connecting the 2 marine ecosystems, but the potential for this source of exposure appears to be limited. Low re-sighting frequencies of coastal ocean dolphins may also suggest that environmental exposure to L. loboi is occurring elsewhere along the Atlantic seaboard. Mazzoil et al. (2010) found minimal interaction between the southern IRL estuary dolphins (Sebastian to St. Lucie Inlets) and the coastal Atlantic population(s). This lack of movement between coastal and estuarine habitats suggests a low potential for disease transmission between the 2 populations.

Exposure to environmental chemicals such as mercury (Noke-Durden et al. 2007, Stavros et al. 2007, 2008) may lead to immune compromise in the resident IRL dolphins and account for the higher prevalence in this population. Reports from other countries where lacaziosis has been reported support the hypothesis that environmental contamination may increase risk for this fungal disease in dolphins (Van Bressem et al. 2007, 2009). Dolphin health assessments have not been conducted along the Florida Atlantic east coast, so the status of their immune system function remains uncertain. Since lacaziosis appears to have a wider geographic distribution than previously assumed, it is nec- 
essary to continue to monitor and study the disease as it may extend its reach into other ecosystems.

Acknowledgements. This research was conducted under National Marine Fisheries Service Scientific Research Permit No. 998-1678, issued to G.D.B. Support was provided by funds from the Florida 'Protect Wild Dolphins' specialty license plate program. Appreciation is extended to: Elisabeth Howells for assistance with data analysis, Malcolm deSieyes and Colby Lawrence for assistance with field work, and Nelson Beaman for database support.

\section{LITERATURE CITED}

Belone AF, Madeira S, Rosa PS, Opromolla DV (2002) Experimental reproduction of the Jorge Lobo's disease in BALB/C mice inoculated with Lacazia loboi obtained from a previously infected mouse. Mycopathologia 155:191-194

Bermudez L, Van Bressem MF, Reyes-Jaimes O, Sayegh AJ, Paniz-Mondolfi AE (2009) Lobomycosis in man and lobomycosis-like disease in bottlenose dolphin, Venezuela. Emerg Infect Dis 15:1301-1303

Bossart GD (1984) Suspected acquired immunodeficiency in an Atlantic bottlenose dolphin with chronic-active hepatitis and lobomycosis. J Am Vet Med Assoc 185:1413-1415

Bossart GD, Meisner R, Varela R, Mazzoil M and others (2003) Pathologic findings in stranded Atlantic bottlenose dolphins (Tursiops truncatus) from the Indian River Lagoon, Florida. Fla Sci 6:226-238

> Caldwell DK, Caldwell MC, Woodard JC, Woodard JC and others (1975) Lobomycosis as a disease of the Atlantic bottlenose dolphin (Tursiops truncatus Montagu, 1821). Am J Trop Med Hyg 24:105-114

$>$ Cowan DF (1993) Lobo's disease in a bottlenose dolphin (Tursiops truncatus) from Matagorda Bay, Texas. J Wildl Dis 29:488-489

De Vries GA, Laarman JJ (1973) A case of Lobo's disease in the dolphin Sotalia guianensis. Aquat Mamm 1:26-33

Elsayed S, Kuhn SM, Barber D, Church DL, Adams S, Kasper R (2004) Human case of lobomycosis. Emerg Infect Dis 10: 715-718

Fuchs J, Milbradt R, Pecher SA (1990) Lobomycosis (keloidal blastomycosis): case reports and overview. Cutis 46: 227-234

Kiszka J, Van Bressem MF, Pusineri C (2009) Lobomycosislike disease and other skin conditions in Indo-Pacific bottlenose dolphins Tursiops aduncus from the Indian Ocean. Dis Aquat Org 84:151-157

Marine Resources Council of East Florida (MRC) (2003) Indian River Lagoon Watch, water quality data. Available at www.mrcirl.org/water/salinity.html (accessed February 19, 2008)

Mazzoil M, McCulloch SD, Defran RH (2005) Observations on the site fidelity of bottlenose dolphins (Tursiops truncatus) in the Indian River Lagoon, Florida. Fla Sci 68:217-227

Mazzoil M, Murdoch ME, Bechdel SE, Howells E and others (2008) Home ranges of bottlenose dolphins (Tursiops truncatus) in the Indian River Lagoon, Florida: environmental correlates and implications for the interpretation of health status. EcoHealth 5:278-288

Mazzoil M, McCulloch SD, Defran RH, Murdoch ME (2004) Use of digital photography and analysis of dorsal fins for photo-identification of bottlenose dolphins. Aquat Mamm 30:209-219

Mazzoil M, Murdoch ME, Reif JS, Bechdel SE and others (2010) Site fidelity and movement of bottlenose dolphins
(Tursiops truncatus) on Florida's east coast: Atlantic Ocean and Indian River Lagoon Estuary. Fla Sci (in press)

Migaki G, Valerio MG, Irvine B, Garner FM (1971) Lobo's disease in an Atlantic bottle-nosed dolphin. J Am Vet Med Assoc 159:578-582

Murdoch ME, Reif JS, Mazzoil M, McCulloch SD, Fair PA, Bossart GD (2008) Lobomycosis in bottlenose dolphins (Tursiops truncatus) from the Indian River Lagoon, Florida: estimation of prevalence, temporal trends and spatial distribution. EcoHealth 5:289-297

Noke-Durden W, Stolen MK, Adams DH, Stolen ED (2007) Mercury and selenium concentrations in stranded bottlenose dolphins from the Indian River Lagoon system, Florida. Bull Mar Sci 81:37-54

Noke-Durdon W, St. Leger J, Stolen M, Mazza T, Londono C (2009) Lacaziosis in bottlenose dolphins (Tursiops truncatus) in the Indian River Lagoon, Florida, USA. J Wildl Dis 45:849-856

Reif JS, Mazzoil MS, McCulloch SD, Varela RA, Fair PA, Bossart GD (2006) Lobomycosis in Atlantic bottlenose dolphins (Tursiops truncatus) from the Indian River Lagoon, Florida. J Am Vet Med Assoc 228:104-108

Reif JS, Peden-Adams MM, Romano TA, Rice CD, Fair PA, Bossart GD (2008) Immune dysfunction in Atlantic bottlenose dolphins (Tursiops truncatus) with lacaziosis. Med Mycol 4:1-11

> Rodriguez-Toro G (1993) Lobomycosis. Int J Dermatol 32: 324-332

> Rosa PS, Soares CT, Belone AFF, Vilela R, Ura S, Filho MC, Mendoza L (2009) Accidental Jorge Lobo's disease in a worker dealing with Lacazia loboi infected mice: a case report. J Med Case Reports 3:67-72

Rotstein DS, Burdett LG, McLellan W, Schwacke L and others (2009) Lobomycosis in offshore bottlenose dolphins (Tursiops truncatus), North Carolina. Emerg Infect Dis 15: 588-590

Simõse-Lopes PCS, Paula GS, Both MC, Xavier FM, Scaramello AC (1993) First case of lobomycosis in a bottlenose dolphin from Southern Brazil. Mar Mamm Sci 9: 329-331

Stavros HC, Bossart GD, Hulsey TC, Fair PA (2007) Trace element concentrations in skin of free-ranging bottlenose dolphins (Tursiops truncatus) from the southeast Atlantic coast. Sci Total Environ 388:300-315

Stavros HC, Bossart GD, Hulsey TC, Fair PA (2008) Trace element concentrations in blood of free-ranging bottlenose dolphins (Tursiops truncatus): influence of age, sex and location. Mar Pollut Bull 56:348-379

> Symmers WS (1983) A possible case of Lobo's disease acquired in Europe from a bottle-nosed dolphin (Tursiops truncatus). Bull Soc Pathol Exot Filiales 76:777-784

Taborda PR, Taborda VA, McGinnis MR (1999) Lacazia loboi gen. nov., comb. nov., the etiologic agent of lacaziosis. J Clin Microbiol 37:2031-2033

Torres LG, Rosel PE, D'Agrosa C, Read AJ (2003) Improving management of overlapping bottlenose dolphin ecotypes through spatial analysis and genetics. Mar Mamm Sci 19: 502-514

Van Bressem MF, Van Waerebeek KV, Reyes JC, Felix J and others (2007) A preliminary overview of skin and skeletal diseases and traumata in small cetaceans from South American waters. Lat Am J Aquat Mamm 6:7-42

Van Bressem MF, Santos MCO, Oshima JEF (2009) Skin diseases in Guiana dolphins (Sotalia guianensis) from the Paranaguá estuary, Brazil: a possible indicator of a compromised marine environment. Mar Environ Res 67:63-68

Woodard JC (1972) Electron microscopic study of lobomycosis (Loboa loboi). Lab Invest 27:606-612

Submitted: April 14, 2010; Accepted: August 30, 2010

Proofs received from author(s): October 18, 2010 